\title{
Evaluation of a novel deep tissue transvaginal near-infrared laser and applicator in an ovine model
}

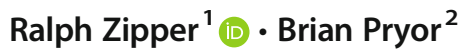 \\ Received: 1 December 2020 / Accepted: 2 April 2021 / Published online: 14 April 2021 \\ (C) The Author(s) 2021
}

\begin{abstract}
Photobiomodulation therapy (PBMT) is an effective means of treating muscle spasm and pain. A novel near-infrared laser system has been commercialized for the treatment of myofascial pelvic pain in women (SoLá Therapy, UroShape, LLC). This study was undertaken to determine if this device is capable of delivering therapeutic levels of irradiance to the pelvic muscles and to identify the surface irradiance required to achieve this goal. This novel class IV near-infrared laser and transvaginal applicator were used to deliver near-infrared light energy through the vaginal mucosa of an adult Suffolk/Dorset Ewe. Irradiance was measured on the surface of the levator ani muscle, inside the levator ani muscle, and inside the bladder. Measurements were taken at powers of $5 \mathrm{~W}$ and $0.5 \mathrm{~W} .3 .0 \%$ of vaginal surface irradiance was measured inside of the levator ani muscle. $4.4 \%$ of vaginal surface irradiance was measured inside the bladder. At $5 \mathrm{~W}$, the novel laser system provided a surface irradiance of $738 \mathrm{~mW} / \mathrm{cm}^{2}$. At 0.5 $\mathrm{W}$, the system provided a surface irradiance of $74 \mathrm{~mW} / \mathrm{cm}^{2}$. A novel class IV near-infrared laser and transvaginal applicator delivered therapeutic irradiance to the levator ani muscle and bladder of an anesthetized ewe at a power setting of $5 \mathrm{~W}$. A power setting of $0.5 \mathrm{~W}$ failed to deliver therapeutic energy into either the levator ani muscle or bladder. Clinical applications targeting deeper tissues such as the pelvic muscles and or bladder should consider power settings that exceed $0.5 \mathrm{~W}$ and or irradiance of $\geq$ $75 \mathrm{~mW} / \mathrm{cm}^{2}$.
\end{abstract}

Keywords Photobiomodulation $\cdot$ Pelvis $\cdot$ Pain $\cdot$ Irradiance $\cdot$ Therapy

\section{Introduction}

Thousands of published laboratory studies and hundreds of published randomized controlled trials have described and defined the beneficial effects of near-infrared (NIR) light energy on living tissue, photobiomodulation [1]. The benefits of NIR energy have been demonstrated on conditions including sprain and strains, post-surgical pain, whiplash, muscular back pain, radiculopathy, tendinitis, and chronic conditions such as osteoarthritis rheumatoid arthritis, neck and back pain, epicondylitis, carpal tunnel syndrome, tendinopathy, fibromyalgia, plantar fasciitis, and chronic regional pain syndrome, as well as neuropathic pain conditions such as postherpetic

Ralph Zipper

ralph.zipper@uroshape.com

1 UroShape, LLC, 200 S. Harbor City Blvd, Suite 401, Melbourne, FL 32901, USA

2 Litecure, LLC, 101 Lukens Dr, STE A, New Castle, DE 19720, USA neuralgia, trigeminal neuralgia, and diabetic neuropathy [1]. Cotler et al., in their review of the scientific and medical literature, including nearly 100 publications, noted that "The longterm effects of low-level laser therapy (NIR) occur within a week or two and can last for months and sometimes years as a result of improved tissue healing." [1]. These authors also pointed out that there are four targets of NIR energy, trigger points to reduce tenderness and relax contracted muscle fibers, nerves to induce analgesia, the site of injury to promote healing, remodeling, and reduce inflammation, and lymph nodes to reduce edema and inflammation.

It is estimated that approximately $14 \%$ of adult women suffer from chronic pelvic pain (CPP) [2]. A recent study of almost 50,000 female US veterans found a 30\% incidence of CPP and a $16.8 \%$ incidence of opioid use amongst sufferers [3]. The incidence of opioid use amongst CPP patients in the general population is consistent with the military cohort [4]. The majority of CPP sufferers share a treatable pathology, hypertonicity, and tenderness of the pelvic muscles, levator myalgia (myofascial pelvic pain). It is estimated that 60 to $85 \%$ of women with CPP have levator myalgia $[4,5]$. 
Alleviation of this tender pelvic muscle hypertonicity is the mainstay of CPP treatment. Unfortunately, randomized controlled trials have failed to identify an effective stand-alone treatment. Although many patients benefit from skilled manual therapy (PT) as part of a multimodality treatment regimen, access is limited [6]. Additionally, results of physical therapy are less than optimal, with recent studies finding less than $40 \%$ pain reduction $[7,8]$. Factors including the length of physical therapy treatments and or discomfort may contribute to low patient compliance [9]. The delivery of therapeutic doses of NIR energy to the pelvic muscles may represent a muchneeded alternative treatment for those suffering from CPP.

As with medications, the correct dose of NIR energy must be delivered over the correct amount of time to achieve the desired outcome. Numerous investigators have reported optimal irradiance and fluence. Bolton et al. noted that although $810 \mathrm{~nm}$ irradiance of $800 \mathrm{~mW} / \mathrm{cm}^{2}$ at a fluence of $2.4 \mathrm{~J} / \mathrm{cm}^{2}$ produced greater cell proliferation than irradiance of $400 \mathrm{~mW} /$ $\mathrm{cm}^{2}$, the higher irradiance lost effect at $7.2 \mathrm{~J} / \mathrm{cm}^{2}[10]$. However, at $400 \mathrm{~mW} / \mathrm{cm}^{2}$ and $7.2 \mathrm{~J} / \mathrm{cm}^{2}$, proliferation remained significantly increased. More recently, Anders et al. found optimal effects at irradiances between $10 \mathrm{~mW} /$ $\mathrm{cm}^{2}$ and $50 \mathrm{~mW} / \mathrm{cm}^{2}$ delivered to a fluence of $200 \mathrm{~mJ} / \mathrm{cm}^{2}$ $[11,12]$. Although an underreporting of irradiance by investigators in the field has hastened the development of a precisely defined dosing regimen, ideal irradiance most likely exists in the range of $10 \mathrm{~mW} / \mathrm{cm}^{2}$ to $400 \mathrm{~mW} / \mathrm{cm}^{2}$, and ideal fluence most likely exists in the range of 0.075 to $8.0 \mathrm{~J} / \mathrm{cm}^{2}$. This dosing must occur at the level of the target tissue and not the overlying skin or mucous membrane. Only a small fraction of the energy applied to the skin or mucous membrane of an organism will reach the target tissue. Hence, the ideal power settings of a laser can only be determined by knowing both the irradiance at the level of the skin and the percentage of the irradiance that will reach the target tissue. Although there may be a consistent pattern of energy decay per millimeter of various tissue types traversed en route to a target tissue, an estimate of such decay is best made for each specific target. The pathway to each unique target tissue represents pathways through unique chromophores. The primary objective of this study is to determine the irradiance needed at the surface of the vaginal mucosa to achieve therapeutic irradiance at the levels of the levator ani muscle and bladder. A secondary endpoint of this study is to determine if this novel transvaginal infrared laser system is capable of delivering such irradiance. As it is critical to incorporate the absorption of water and blood in determining the depth of penetration, a cadaveric study would be insufficient. This study utilizes a live ovine model.

The vaginal structure of sheep is considered similar in structure to humans and provides a sufficiently analogous system for conducting gynecological procedures. Recent histological evaluation of the ovine mucosa and surgical anatomic dissection has validated this analogy $[13,14]$. Compared to smaller species, the size of the ovine model also allows for convenient testing of an index device as designed for use in humans. Considering these factors in conjunction with the availability of the ovine model makes this the preferred model for testing a transvaginal treatment device. This research study was conducted in compliance with the requirements of the Animal Welfare Act and amendments and standards in the Guide for the Care and the Use of Laboratory Animals, ILAR, National Academy Press, latest edition as well as GLP, guidelines for nonclinical laboratory studies as described in the Code of Federal Regulations, 21 Part 58, and with any applicable amendments. The study was performed in an Association for the Assessment and Accreditation of Laboratory Animal Care, International (AAALAC) accredited facility and approved by the Institutional Animal Care and Use Committee (IACUC).

\section{Materials and methods}

One healthy, non-pregnant sheep of reproductive maturity was enrolled. Prior to enrollment in the procedure, the animal was housed separately from the opposite sex. Administration of vaginal ointments and medications was avoided for 1 week prior to the procedure. The animal received intravenous sedation followed by the induction of general endotracheal anesthesia. Following induction of anesthesia, the animal was placed in the dorsal lithotomy position. Examination of the vagina demonstrated a normal-appearing mucosa without evidence of trauma or infection. The vaginal length was measured at $11 \mathrm{~cm}$.

The laser calibration was confirmed within $40 \mathrm{~h}$ of the study and again on the morning of the study. Irradiance measurements were made utilizing the BK Precision 2712 Digital Multimeter and the B\&W Tek NIR Power Probe (Fig. 1).

High sensitivity sensors $\left(1 \mu \mathrm{W} / \mathrm{cm}^{2}\right)$ and a low sensitivity sensors $\left(500 \mathrm{~mW} / \mathrm{cm}^{2}\right)$ were utilized.

This meter had been calibrated within 7 days of the study by the factory engineers. The Probes were bench tested with the calibrated laser and a control laser (LTS 1500, LiteCure, LLC) for accuracy on the day of the study.

Mucosal surface irradiance was measured by placing the transmitting section of the delivery device (vaginal probe) directly over a Power Probe. Measurements were made at powers of 0.5 and $5.0 \mathrm{~W}$. Next, a 3-cm incision was created in the perineal skin. An American Board of Obstetrician and Gynecologist-certified pelvic reconstructive surgeon performed a transperineal dissection down to the levator ani muscle directly beneath the mid vaginal vault. A $3 \times 2 \times 1.5 \mathrm{~mm}$ Power Probe was placed on the surface of the levator ani muscles. The distance from the perineum to the Power Probe was measured $(6 \mathrm{~cm})$. The measurement was used to facilitate vaginal placement of the energy delivery device directly over 


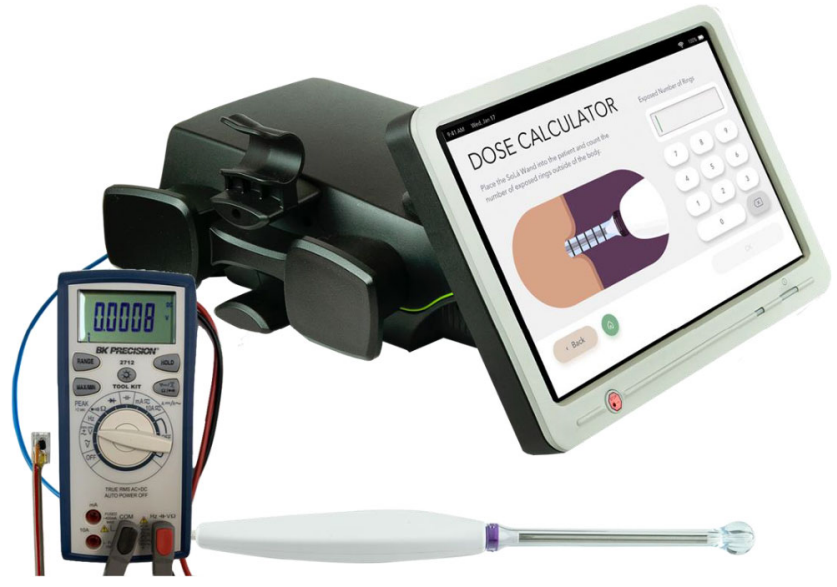

Fig. 1 The SoLá Pelvic Therapy Laser System and its transvaginal delivery system. The delivery system consists of a reusable handpiece and proprietary laser fiber that radiates energy perpendicular to the fiber. The distal handpiece is covered by a single-use, sterile, wand with a bulbous tip. Inset is the BK 2712 Precision Multimeter with a custom B\&W Tek near-infrared Power sensor. These sensors were implanted in the subject

the Power Probe. A second Power Probe was placed through a tunnel into the belly of the muscle. This probe was placed $1 \mathrm{~cm}$ proximal and $1 \mathrm{~cm}$ to the right of the more superficial Power Probe. The energy delivery device was placed in the vagina over the superficial (surface) levator ani Power Probe. Irradiance measurements were made at $5.0 \mathrm{~W}$ and then $0.5 \mathrm{~W}$. After $5 \mathrm{~min}$, the measurements were repeated in reverse order ( $0.5 \mathrm{~W}$ first). The energy device was next placed over the deeper Power Probe, and irradiance measurements were made at $0.5 \mathrm{~W}$ and then $5.0 \mathrm{~W}$. After $5 \mathrm{~min}$, the measurements were repeated in reverse order (5.0 W first). Power Probe was next placed through the urethra and into the bladder. The energy device was next placed in the vagina under the bladder Power

Table 1 Irradiance at target tissue. Irradiance at target tissue provides the laser power in watts (W), a description of each sensor's position in the subject, the depth of this position from the vaginal mucosa in millimeters, the irradiance at this depth in milliwatts per centimeter squared, and the
Probe. Irradiance measurements were made at $5.0 \mathrm{~W}$ and 0.5 W. After $5 \mathrm{~min}$, the measurements were repeated in reverse order $(0.5 \mathrm{~W}$ first). The bladder was next catheterized of $50 \mathrm{cc}$ of urine. Following euthanasia, the posterior vaginal wall, rectum, and levator ani were excised in-block, and depth measurements were taken (see Table 1).

\section{Results}

Approximately $12.5 \%$ of the irradiance at the vaginal mucosa reached the surface of the levator ani muscle. Approximately $3 \%$ of the initial irradiance reached the center of the levator ani muscle. At a power of $5 \mathrm{~W}$, approximately $4.5 \%$ of the irradiance reached the bladder. At $0.5 \mathrm{~W}$, the irradiance reaching the bladder was too low to be detected by the Power Probe (Table 1). Postmortem measurements were made of the harvested posterior pelvic tissues. The distance from the vaginal mucosal surface to the levator ani was $7 \mathrm{~mm}$. The distance to the mid-levator ani muscle belly was $10 \mathrm{~mm}$. The levator ani thickness was $4 \mathrm{~mm}$.

\section{Discussion}

Numerous investigators have reported on the dose-response effect associated with the application of NIR light to living tissue. Although this effect is sometimes referred to as the "biphasic dose-response" effect of light therapy, there is nothing novel about this effect. This effect has been well understood in the pharmaceutical industry for over a century. In the simplest of terms, too small of a dose does nothing. A slightly larger dose may have an effect. A bit more gets the desired effect, and a bit more starts to harm. Take the correct dose over irradiance at the surface in milliwatts per centimeter squared. The percentage of power lost at depth is described as "irradiance reaching depth"

\begin{tabular}{|c|c|c|c|c|c|}
\hline Power setting (W) & Sensor depth (mm) & $\begin{array}{l}\text { Mean irradiance at } \\
\text { vaginal mucosa }\left(\mathrm{mW} / \mathrm{cm}^{2}\right)\end{array}$ & $\begin{array}{l}\text { Mean irradiance } \\
\text { at depth }\left(\mathrm{mW} / \mathrm{cm}^{2}\right)\end{array}$ & Sensor position & $\begin{array}{l}\text { Irradiance } \\
\text { reaching depth }\end{array}$ \\
\hline 5 & 7.5 & 738 & 92 & $\begin{array}{l}\text { Surface of levator ani- } \\
\text { beneath mid vaginal vault }\end{array}$ & $12.47 \%$ \\
\hline 0.5 & 7.5 & 74 & $9.5^{*}$ & $\begin{array}{l}\text { Surface of levator ani- } \\
\text { beneath mid vaginal vault }\end{array}$ & $12.84 \% *$ \\
\hline 5 & 10 & 738 & 22 & $\begin{array}{l}\text { Mid levator ani muscle- } \\
\text { beneath mid vaginal vault }\end{array}$ & $2.98 \%$ \\
\hline 0.5 & 10 & 74 & $0 * *$ & $\begin{array}{l}\text { Mid levator ani muscle-- } \\
\text { beneath mid vaginal vault }\end{array}$ & $0 * *$ \\
\hline 5 & N/A & 738 & 33 & Floating in bladder w/ $50 \mathrm{cc}$ urine & $4.47 \%$ \\
\hline 0.5 & N/A & 74 & 0.02 & Floating in bladder $\mathrm{w} / 50 \mathrm{cc}$ urine & $0.03 \%$ \\
\hline
\end{tabular}

Three measurements were made at each location. Variation was $\leq 0.5 \mathrm{~mW}$. *Sensor error is $\pm 0.0005 \mathrm{~W}$. **The Power Probe sensors fractured in the tissue tunnel. A measurement was not available 
too long of a time interval, and there may be little or no effect, but take that same dose all at once, and you may be harmed. In summary, the correct amount of NIR energy per unit area must be delivered over the correct amount of time. In the dosing of laser energy, these two variables are described by irradiance (power density) and fluence (irradiance $\times$ time).

Although both a pilot study and clinical experience have demonstrated the safety and efficacy of this novel transvaginal infrared laser system, this is the first study to document irradiance at the level of target pelvic tissues. This study demonstrates that a novel class IV NIR laser with a novel transvaginal delivery system is capable of delivering therapeutic doses of NIR energy to at least $10 \mathrm{~mm}$ below the vaginal mucosa. This depth is sufficient to reach into the human levator ani muscles and bladder, which are found at depths and thicknesses similar to that of the studied animal [15].

The irradiance loss identified in our study is similar to the irradiance loss reported by Anders et al. Ander found that approximately $3 \%$ of NIR light transmitted through rabbit epithelium reached the targeted perineal nerve (12 $\mathrm{mm}$ deep) $[11,12]$. This was nearly identical to our finding at $10 \mathrm{~mm}$. Although each area of the body represents a potential new challenge secondary to varying tissue thickness and chromophores, this variation may represent less of a challenge to class IV NIR lasers. Our study validates the finding of Anders. A low-power laser in the milliwatt range is unlikely to deliver therapeutic dosing to deeper tissues.

Although the loss of irradiance per unit depth appears to be similar across different powers, there was an unexpectedly large drop at $500 \mathrm{~mW}$ when measured inside the bladder. Lower irradiances may be more vulnerable to the refraction encountered in urine. Based on the loss of irradiance documented at $5 \mathrm{~W}, 500 \mathrm{~mW}$ should result in irradiance of 2.2 and $3.3 \mathrm{~mW} / \mathrm{cm}^{2}$ in the levator muscle and bladder. One must remember that the surface irradiance of most class IIIB (milliwatt) lasers is confined to small spot sizes. Small spot sizes impair penetration and will unlikely be able to achieve the $3-4.5 \%$ irradiance at the target depths achieved by the studied system herein. Even if such transmission could be achieved, the small spot size would require treatment times that could be prohibitive.

The studied class IV NIR laser is capable of achieving a power of $15 \mathrm{~W}$. Its novel transvaginal delivery system disperses $810 \mathrm{~nm}$ and $980 \mathrm{~nm}$ light in a 360-degree array. This study demonstrates that this novel system is capable of delivering therapeutic irradiances to and through the levator ani muscle and into the bladder (Table 2). This finding further validates the encouraging therapeutic responses of CPP patients who have been treated with the system since July of 2019.

One weakness of this study is that the data was collected from a live ewe rather than a human. Although the tissues and anatomy are remarkably similar, variations in irradiance
Table 2 Irradiance at surface and inside levator ani muscle by power setting. This table provides irradiance measurements in milliwatts per centimeter squared at the surface of the vaginal mucosa, and the irradiance measurements in milliwatts per centimeter squared reaching the middle portion (in depth) of the levator ani. These measurements are provided at laser power settings of 1, 2, 3, 4, 5, and $6 \mathrm{~W}$

\begin{tabular}{lll}
\hline Power $(\mathrm{W})$ & $\begin{array}{l}\text { Surface irradiance } \\
\left(\mathrm{mW} / \mathrm{cm}^{2}\right)\end{array}$ & $\begin{array}{l}\text { Irradiance inside } \\
\text { levator ani* }\left(\mathrm{mW} / \mathrm{cm}^{2}\right)\end{array}$ \\
\hline 1 & 166 & 4.95 \\
2 & 388 & 11.57 \\
3 & 522 & 15.56 \\
4 & 643 & 19.17 \\
5 & 738 & 22.00 \\
6 & 998 & 29.75 \\
\hline
\end{tabular}

*5 W irradiance measured. Other values calculated based on $5 \mathrm{~W}$ Power Probe measurement

transmission may exist. An additional limitation remains the small pool of NIR dose-response data available for the treatment of pelvic muscle spasm and bladder symptoms. Although the data collected during the last year of commercial use of this novel device suggest that the irradiance generated at $5 \mathrm{~W}$ is therapeutic and the irradiance generated at $.5 \mathrm{~W}$ will not be therapeutic in the transvaginal treatment of levator myalgia (myofascial pelvic pain), future clinical studies should gather additional longitudinal data at power settings at, below, and above $5 \mathrm{~W}$.

Acknowledgements The authors would like to thank Mr. Kevin Richardson and Mr. Steven Bowers for their participation in the organization and completion of the study.

Author contribution Zipper: project development, data collection, management of data analysis, manuscript writing

Pryor: project development, data collection, management of data analysis, manuscript writing

Funding This study was paid for by UroShape, LLC, the manufacturers of the SoLá Pelvic Therapy Laser System. Dr. Zipper is the CEO of UroShape, LLC, and holds a financial interest in the company. Dr. Pryor is the CEO of LiteCure, LLC, the supplier of the diode laser used in the manufacture of the SoLá Pelvic Laser System. Dr. Pryor has a financial interest in UroShape, LLC. Both Dr. Zipper and Dr. Pryor sit on the Board of Directors of UroShape, LLC.

Availability of data and material Data available within the article or its supplementary materials

Code availability Not applicable

\section{Declarations}

Conflict of interest Ralph Zipper, MD, FPMRS, is the CEO of UroShape, LLC, the manufacturer of the deep tissue transvaginal near- 
infrared laser and applicator. Dr. Zipper has a financial interest in UroShape, LLC.

Brian Pryor, Ph.D., is the CEO of Litecure, LLC, the supplier of the diode laser used in the manufacture of the UroShape laser system. Dr. Pryor has a financial interest in UroShape, LLC.

Open Access This article is licensed under a Creative Commons Attribution 4.0 International License, which permits use, sharing, adaptation, distribution and reproduction in any medium or format, as long as you give appropriate credit to the original author(s) and the source, provide a link to the Creative Commons licence, and indicate if changes were made. The images or other third party material in this article are included in the article's Creative Commons licence, unless indicated otherwise in a credit line to the material. If material is not included in the article's Creative Commons licence and your intended use is not permitted by statutory regulation or exceeds the permitted use, you will need to obtain permission directly from the copyright holder. To view a copy of this licence, visit http://creativecommons.org/licenses/by/4.0/.

\section{References}

1. Cotler HB, Chow RT, Hamblin MR, Carroll J (2015) The use of low-level laser therapy (LLLT) for musculoskeletal pain. MOJ Orthop Rheumatol 2(5). https://doi.org/10.15406/mojor.2015.02. 00068

2. Mathias SD, Kuppermann M, Liberman RF, Lipschutz RC, Steege JF (1996) Chronic pelvic pain: prevalence, health-related quality of life, and economic correlates. Obstet Gynecol 87(3):321-327. https://doi.org/10.1016/0029-7844(95)00458-0

3. Cichowski SB, Rogers RG, Komesu Y, Murata E, Qualls C, Murata A, Murata G (2018) A 10-yr analysis of chronic pelvic pain and chronic opioid therapy in the women veteran population. Military Medicine 183(11-12):e635-e640. https://doi.org/10.1093/milmed/ usy114

4. Adams K, Gregory WT, Osmundsen B, Clark A (2013) Levator myalgia: why bother? Int Urogynecol J 24(10):1687-1693. https:// doi.org/10.1007/s00192-013-2089-8

5. Meister MR, Sutcliffe S, Badu A, Ghetti C, Lowder JL (2019) Pelvic floor myofascial pain severity and pelvic floor disorder symptom bother: is there a correlation? Am J Obstet Gynecol 221(3):235 e231-235 e215. https://doi.org/10.1016/j.ajog.2019.07. 020

6. Wein AJ (2015) Re: Prevalence of myofascial chronic pelvic pain and the effectiveness of pelvic floor physical therapy. J Urol 194(3): 730. https://doi.org/10.1016/j.juro.2015.06.065

7. Oyama IA, Rejba A, Lukban JC, Fletcher E, Kellogg-Spadt S, Holzberg AS, Whitmore KE (2004) Modified Thiele massage as therapeutic intervention for female patients with interstitial cystitis and high-tone pelvic floor dysfunction. Urology 64(5):862-865. https://doi.org/10.1016/j.urology.2004.06.065

8. FitzGerald MP, Payne CK, Lukacz ES, Yang CC, Peters KM, Chai TC, Nickel JC, Hanno PM, Kreder KJ, Burks DA, Mayer R, Kotarinos R, Fortman C, Allen TM, Fraser L, Mason-Cover M, Furey C, Odabachian L, Sanfield A, Chu J, Huestis K, Tata GE, Dugan N, Sheth H, Bewyer K, Anaeme A, Newton K, Featherstone W, Halle-Podell R, Cen L, Landis JR, Propert KJ, Foster HE Jr, Kusek JW, Nyberg LM, Interstitial Cystitis Collaborative Research N (2012) Randomized multicenter clinical trial of myofascial physical therapy in women with interstitial cystitis/painful bladder syndrome and pelvic floor tenderness. J Urol 187(6):2113-2118. https://doi.org/10.1016/j.juro.2012.01.123

9. Woodburn KL, Tran MC, Casas-Puig V, Ninivaggio CS, Ferrando CA (2019) Compliance with pelvic floor physical therapy in patients diagnosed with high-tone pelvic floor disorders. Female Pelvic Med Reconstr Surg. https://doi.org/10.1097/SPV. 0000000000000732

10. Young S, Bolton P, Dyson M, Harvey W, Diamantopoulos C (1989) Macrophage responsiveness to light therapy. Lasers Surg Med 9(5):497-505. https://doi.org/10.1002/1sm.1900090513

11. Anders JJ, Moges H, Ilev, Waynan R, Longo L (2007) Light interaction with human central nervous system progenitor cells. Paper presented at the NAALT conference proceedings

12. Anders JJ, Moges H, Wu X, Erbele ID, Alberico SL, Saidu EK, Smith JT, Pryor BA (2014) In vitro and in vivo optimization of infrared laser treatment for injured peripheral nerves. Lasers Surg Med 46(1):34-45. https://doi.org/10.1002/lsm.22212

13. Mansoor A, Curinier S, Campagne-Loiseau S, Platteeuw L, Jacquetin B, Rabischong B (2017) Development of an ovine model for training in vaginal surgery for pelvic organ prolapse. Int Urogynecol J 28(10):1595-1597. https://doi.org/10.1007/s00192017-3292-9

14. Vincent KL, Bourne N, Bell BA, Vargas G, Tan A, Cowan D, Stanberry LR, Rosenthal SL, Motamedi M (2009) High resolution imaging of epithelial injury in the sheep cervicovaginal tract: a promising model for testing safety of candidate microbicides. Sex Transm Dis 36(5):312-318. https://doi.org/10.1097/OLQ. 0b013e31819496e4

15. Tunn R, Delancey JO, Howard D, Ashton-Miller JA, Quint LE (2003) Anatomic variations in the levator ani muscle, endopelvic fascia, and urethra in nulliparas evaluated by magnetic resonance imaging. Am J Obstet Gynecol 188(1):116-121. https://doi.org/10. 1067/mob.2003.58

Publisher's note Springer Nature remains neutral with regard to jurisdictional claims in published maps and institutional affiliations. 